\title{
De impact van digitale campagnemiddelen op de personalisering van politieke partijen in Nederland (2010-2014)
}

\author{
Kristof Jacobs en Niels Spierings
}

ABSTRACT: The Impact of Digital Campaign Instruments on the
Personalization of Political Parties in the Netherlands (2010-2014)

Politicians have started to use social media more often. As such media induce personal campaigning, one might expect more personalization to follow. We explore what type of personalization social media stimulate, whether this is different for Twitter and Facebook and analyze the role of parties. We make use of quantitative and qualitative data about the Netherlands (2010-2014). We find that while theoretically the impact of social media may be big, in practice it is fairly limited: more presidentialization but not more individualization (though Twitter might increase the focus on other candidates slightly). The difference between theory and practice seems largely due to the parties. They adopt a very ambiguous stance: though they often stimulate candidates to use social media, they want to keep control nonetheless.

KEYWORDS: personalization, social media, election campaigns, party politics

\section{Introductie}

Politieke partijen maken steeds meer gebruik van digitale communicatiemiddelen zoals Twitter en Facebook (Gibson, Römmele \& Williamson, 2014). Vele partijen geloven dat het een bijdrage kan leveren aan een verkiezingsoverwinning. Dat geloof is niet geheel onterecht, zo blijkt. Steeds meer onderzoek toont aan dat het gebruik van sociale media tijdens de campagne, en dan vooral van Twitter, een bescheiden bijdrage kan leveren aan het succes van individuele kandidaten (Gibson 
\& McAllister, 2012; Hansen \& Kosiara-Pedersen, 2014; Koc-Michalska et al., 2014; Kruikemeier, 2014; Spierings \& Jacobs, 2014; Sudulich, Baccini \& Wall, 2012). Een gevolg hiervan is een groeiende nadruk op persoonlijke campagnes.

Deze relatief nieuwe digitale communicatiemiddelen lijken een nieuwe campagnestijl te stimuleren: "personal campaigning” (Vergeer, Hermans \& Sams, 2013, pp. 480-481). Zoals dit label suggereert, zou deze nieuwe campagnestijl tot meer personalisering van de politiek kunnen leiden. Het is echter onduidelijk tot welk soort personalisering: leidt gebruik van sociale media tot meer nadruk op individuele kandidaten in het algemeen - "general visibility" (Van Aelst, Schaefer \& Stanyer, 2011, p. 207; hierna 'diffuse individualisering') - of enkel tot nadruk op de topkandidaat - "concentrated visibility" of "presidentialization" (zie de introductie van dit themanummer). Voor beide soorten personalisering zijn theoretische argumenten te geven, maar het is niet duidelijk of dit theoretische potentieel tot personalisering in de praktijk tot uiting komt. Daarnaast is onduidelijk of alle sociale media een gelijk potentieel en effect hebben. Het grootste deel van het socialemediaonderzoek focust enkel op Twitter (Jacobs \& Spierings, 2014; Kruikemeier, 2014; Peterson, 2012; Vergeer \& Hermans, 2013; Vergeer et al., 2013) of behandelt Facebook en Twitter als één (Hansen \& Kosiara-Pedersen, 2014; Koc-Michalska et al., 2014). Tot slot blijft de rol van partijen vaak onderbelicht en gaat men er impliciet vanuit dat politici onafhankelijk handelende actoren zijn. Hoewel er relatief veel onderzoek is gedaan naar welke politici een socialemedia-account hebben (bv. Gibson et al., 2014; Vergeer \& Hermans, 2013), nemen deze kwantitatieve analyses moeilijk cijfermatig te meten elementen zoals partijstructuur en partijstrategie niet mee in hun analyses. Zij laten dus een deel van het totaalplaatje buiten beeld. Dit is belangrijk, omdat het niet ondenkbaar is dat sommige partijen hun politici wel degelijk actiever stimuleren om sociale media te gebruiken dan andere partijen.

In deze bijdrage onderzoeken we hoe partijen omgaan met het socialemediagebruik van hun politici en welke strategie ze daarbij hebben. In het bijzonder willen we onderzoeken wat de relatie is tussen de verschillende types partijen, sociale media en de verschuiving van het politieke zwaartepunt van partij naar politicus - personalisering. Voor elk van deze drie onderwerpen formuleren we in het theoretische kader een onderzoeksvraag op basis van hiaten in het bestaande onderzoek. Daarbij verkennen we in het bijzonder hoe Twitter als persoonlijk persbureau en Facebook met zijn complexe algoritmen de relaties tussen partijen, topkandidaten en de andere kandidaten (kunnen) beïnvloeden, en hoe deze personaliseringsprocessen (of het gebrek daaraan) afhankelijk zijn van het type partij en sociale media.

We gebruiken zowel kwantitatieve als kwalitatieve gegevens uit de periode 20102014. De kwantitatieve gegevens stellen ons in staat het gebruik van sociale media van alle partijen te beschrijven. De interviews openen daarna de 'black box' en stellen ons in staat een blik te werpen op de strategieën van de onderzochte partijen. Onze focus ligt op de Nederlandse casus. Nederland is een voorloper op

RES PUBLICA • $2015-1$ 
het gebied van nieuwe technologieën en heeft wat betreft de impact van de voorkeurstem een vrij typisch kiesstelsel dat vergelijkbaar is met de meeste Europese landen. Het is daarom een geschikte casus om ontwikkelingen die andere landen wellicht nog te wachten staan te verkennen. In wat volgt zullen we eerst het personaliseringsdebat en het belang van sociale media en partijstructuur bespreken. Daarna komt de onderzoeksmethode aan bod, gevolgd door een resultatensectie per onderzoeksvraag.

\section{Theoretische achtergrond: presidentialisering, personalisering en sociale media}

\subsection{Personalisering van de politiek}

Personalisering van de politiek is een onderwerp dat zowel binnen de politicologie als de communicatiewetenschap veel aandacht krijgt. De politicologische analyses kijken voornamelijk naar de personalisering van de politieke instituties en verkiezingscampagnes (Colomer, 2011; Karvonen, 2010; McAllister, 2007; Poguntke \& Webb, 2005; Van Holsteyn \& Andeweg, 2012). De meer communicatiewetenschappelijke stukken kijken vooral naar de personalisering van de politiek in de media maar besteden eveneens aandacht aan personalisering van verkiezingscampagnes (Kriesi, 2012; Van Aelst et al., 2011; Vliegenthart, 2012). Beide stromingen maken daarbij hetzelfde onderscheid tussen types personalisering (de labels verschillen soms). Bij de individualisering van de politiek verschuift de aandacht van instituties en organisaties naar individuen en bij de privatisering van de politiek verschuift de aandacht van de politicus als rolbekleder naar de politicus als mens, met meer nadruk op het privéleven van de persoon (vandaar de wat ongelukkige term 'privatisering'). Recent onderzoek naar sociale media van Vergeer, Hermans en Sams wijst erop dat dergelijke media een nieuwe campagnestijl vereisen, met communicatie die "personalized, decentralised and unsupervised" is (Vergeer et al., 2013, pp. 480-481). Ze noemen dit "personal campaigning" (Vergeer et al., 2013, p. 496), wat al een mogelijk verband tussen de verspreiding van sociale media en personalisering suggereert. Maar welke soort personalisering? Op deze vraag geven zij geen antwoord (Vergeer et al., 2013, p. 481).

Het debat over het internet en campagnevoeren biedt enige aanknopingspunten. Terugkerend in een dergelijk onderzoek is de vraag of technologische innovaties het politieke speelveld nivelleren dan wel de positie versterken van personen en partijen die reeds een voorsprong hebben. Dit zogenaamde 'egaliseren versus normaliseren'-debat werd tot voor kort enkel op partijniveau onderzocht, maar recentelijk kijkt men ook naar kandidaten binnen partijen (Jacobs \& Spierings, 2014; Schlozman, Verba \& Brady, 2012). Stellen technologische innovaties de minder 
bekende kandidaten in staat om in te lopen op de meest prominente kandidaten wat betreft bekendheid en aandacht, en uiteindelijk populariteit, stemmen en interne machtsbasis? Onze focus ligt op de eerste stap in het proces: bekendheid en aandacht. Sociale media kunnen mogelijk bijdragen aan een dergelijke nivellering tussen kandidaten binnen partijen. Iedereen kan deze goedkope en laagdrempelige campagnekanalen immers gebruiken (Vergeer et al., 2013). Vooral in landen waar individuele kandidaten over weinig andere persoonlijke campagnemiddelen beschikken kan het effect groot zijn.

Dit raakt direct aan de personalisering van de politiek: wanneer politici massaal sociale media gebruiken en deze bovendien een spillovereffect teweegbrengen naar meer traditionele media, versterkt dit reeds aanwezige tendensen van diffuse personalisering, zeker aangezien journalisten inderdaad zeer actieve gebruikers van sociale media lijken te zijn (Lasorsa, Lewis \& Holton, 2012). Zij gebruiken voornamelijk het platform Twitter en wel om quotes van bekende politici, maar ook controversiële tweets van minder bekende politici, te vergaren voor nieuwsberichten (Peterson, 2012, p. 432). In die zin kan men Twitter vergelijken met de 18e-eeuwse Franse salons waar opinies 'gemaakt' werden. ${ }^{1}$ Of deze (theoretische) potentie van sociale media om diffuse individualisering te stimuleren ook benut wordt door politici is nog een onbeantwoorde vraag. Het is namelijk ook mogelijk dat sociale media gefocuste individualisering bevorderen ( $c f$. normalisering), omdat de benodigde kennis en middelen toch een barrière vormen voor politici die niet professioneel ondersteund worden. Als partijen vanuit hun campagne- en partijgeleide gedachte vooral de prominente politici en lijsttrekkers ondersteunen en stimuleren, wordt dit versterkt. Partijen kunnen zelfs andere kandidaten belemmeren of ontraden sociale media te gebruiken. Kortom, het is onduidelijk wat de invloed van sociale media is op een verschuiving in campagnenadruk van topkandidaten (gefocuste individualisering - of als de focus enkel of de lijsttrekker ligt: presidentialisering) naar alle kandidaten (diffuse individualisering). ${ }^{2}$

Onderzoeksvraag 1: In welke mate zorgt socialemediagebruik voor gefocuste dan wel diffuse personalisering?

\subsection{Verschillende types sociale media: Twitter versus Facebook}

Tot nu toe beschouwden we sociale media als een monolithisch blok, maar het is niet ondenkbaar dat de vaak grote verschillen tussen de diverse types sociale media doorwerken in hun invloed op personalisering. Hierover is bijzonder weinig bekend. Het grootste deel van het socialemediaonderzoek gaat enkel over Twitter (Jacobs \& Spierings, 2014; Kruikemeier, 2014; Peterson, 2012; Vergeer \& Hermans, 2013; Vergeer et al., 2013). Twitter is echter uniek: korte berichten die in de regel openbaar zijn en elkaar in snel tempo ongefilterd opvolgen. Facebook is

RES PUBLICA • $2015-1$ 
anders: privépagina's (tot 5.000 vrienden) zijn in de regel afgesloten, vereisen dat de gebruiker manueel vriendschapsverzoeken goedkeurt en worden vaak gebruikt voor privédoeleinden zoals contact met vrienden en familie. Facebook biedt echter ook specifieke organisatiepagina's aan (verplicht vanaf 5.000 vrienden). Deze zijn onpersoonlijker en worden veel minder voor privézaken gebruikt. Facebook 'straft' bovendien gebruikers die berichten posten die weinig geliked, gedeeld of becommentarieerd worden in zijn algoritme ('Edge Rank'). Facebook is dus een medium dat spaarzamer dient te worden gebruikt en waarvoor één bericht per dag optimaal is. ${ }^{3}$ Datzelfde algoritme filtert boodschappen van de bedrijfspagina's en beloont 'professionelere' berichten die meer kans hebben op een breed bereik zoals infographics of foto's, en op Facebook is aandacht voor berichten te koop. Deze inhoudelijke verschillen tussen Facebook en Twitter kunnen een effect hebben op personaliseringsprocessen. Zo kan het verschil in benodigde hulpmiddelen (zoals kennis) die nodig zijn om succesvol te zijn op Facebook (meer) en Twitter (minder) er bijvoorbeeld toe leiden dat Twitter meer diffuse personalisering faciliteert en Facebook meer geconcentreerde personalisering. De twee studies die Facebook en Twitter onderzoeken maken echter geen onderscheid en aggregeren het gebruik (Hansen \& Kosiara-Pedersen, 2014; Koc-Michalska et al., 2014).

Onderzoeksvraag 2: Is er een verband tussen de verschillende soorten sociale media, in casu Twitter en Facebook, en de verschillende soorten personalisering?

\subsection{Personaliseringspotentieel versus de partijpraktijk}

Ook de Nederlandse politieke partijen zijn wellicht geen monolithisch blok. In de literatuur wordt meestal verwacht dat linkse partijen sociale media anders gebruiken dan rechtse partijen (Vergeer et al., 2013). Groene partijen lijken inderdaad meer gebruik te maken van sociale media en er ook meer baat bij te hebben (Gibson \& McAllister, 2014), maar aangezien het meeste andere onderzoek vindt dat grote partijen (onafhankelijk van hun politieke kleur) sociale media meer gebruiken dan kleinere partijen, lijkt het onderscheid links-rechts verder niet houdbaar (Gibson et al., 2014). Wellicht is de uitzonderingspositie van de groene partijen te verklaren door andere zaken dan ideologie, zoals bijvoorbeeld door het feit dat hun politici, vrijwilligers en kiezers vaker hoogopgeleid en tech-savvy zijn.

Wat betreft het type personalisering, is wellicht nog een andere factor van belang, namelijk de partijorganisatie. Vergeer, Hermans en Sams (2013, p. 481) suggereren: "[o]ne risk is that personalized, decentralized, and unsupervised communications and campaigning might lead to less party control over the politician. Party discipline (...) could subsequently become compromised”. Aangezien sociale media de grip die de partijleiding heeft over de individuele kandidaten verminderen, zijn sociale media vooral voor centraal georganiseerde partijen een potentiële luis in 
de pels. Allereerst kunnen politici via sociale media gemakkelijk en goedkoop een persoonlijke 'machtsbasis' opbouwen. Sociale media zijn dan, om met de woorden van een prominent politicus te spreken, "een persoonlijk ANP" (Partij 9, 3 juli 2013). ${ }^{4}$ Daarmee wordt de politicus in kwestie onafhankelijker van de partij. Tevens zijn sociale media om inhoudelijke redenen mogelijk gevaarlijk voor partijen. Kandidaten die zelf berichten plaatsen, vergroten de kans op blunders. Ook kunnen sociale media verborgen partij-interne meningsverschillen blootleggen. Zeker als we ons realiseren dat journalisten, zoals gezegd, controversiële tweets van minder bekende politici voor hun nieuwsberichten gebruiken en op zoek zijn naar intern conflict (Peterson, 2012). Sociale media vormen daarmee voor alle partijen wel in enige mate een potentieel probleem: allemaal willen ze graag centraal controle houden over de boodschap - zeker in campagnetijd (Norris et al., 1999). Het is dan ook te verwachten dat partijen socialemediagebruik sturen, controleren of aan banden leggen. Logischerwijs vormen sociale media voor sterk en strak centraal georganiseerde partijen echter nog eerder een gevaar dan voor niet-centraal georganiseerde partijen. ${ }^{5}$ Of deze sturing en controle ook daadwerkelijk plaatsvinden en in het bijzonder bij centraal georganiseerde partijen is echter nog niet onderzocht.

Onderzoeksvraag 3: Hoe gaan partijen om met het socialemediagebruik van hun politici en verschilt dit voor gecentraliseerde en niet-gecentraliseerde partijen?

\section{Onderzoeksdesign: multi-method case-study}

\subsection{Casus: Nederlandse politiek en sociale media}

Nederland kent een divers politiek landschap met de laatste jaren een tiental partijen dat de 150 zetels in de Tweede Kamer opeist via een proportioneel kiesstelsel. In de praktijk is er maar één kiesdistrict en kiezers kiezen uit meer dan 500 kandidaten verdeeld over meer dan tien kieslijsten. Een Nederlandse kiezer mag slechts één stem uitbrengen en is er geen lijst met opvolgers, zoals dat in België het geval is. Deze stem is altijd op een kandidaat en kan niet op een lijst als geheel zijn. Dit faciliteert personalisering, aangezien altijd voor een persoon gekozen wordt. Deze stemmen zijn een potentiële route naar directe verkiezing en kunnen de interne macht van een kandidaat verhogen. Als het aantal stemmen een kwart van de kiesdeler overschrijdt, is een kandidaat direct gekozen in de Tweede Kamer (op voorwaarde dat de partij voldoende zetels heeft). Deze zogenoemde voorkeursdrempel lag de laatste verkiezingen rond de 15.700 stemmen (www.kiesraad.nl). Voor drie kandidaten maakte dit in de laatste twee verkiezingen het verschil (2012: Pieter Omtzigt; 2010: Pia Dijkstra en Sabine Uitslag).

RES PUBLICA • $2015-1$ 
In de regel domineren partijen en lijsttrekkers de campagnes. Individuele kandidaten krijgen weinig financiering voor een eigen campagne. Hoewel ze wel erg gericht zijn op de lijsttrekkers, zijn de Nederlandse campagnes niet "candidate-centered" te noemen (Andeweg \& Irwin, 2005, p. 89). Sociale media zijn een relatief nieuw campagnemiddel, zowel op individueel als op partijniveau, maar Nederland is wereldwijd een koploper op het gebied van sociale media. In 2010 had Twitter meer dan 2,5 miljoen gebruikers in Nederland en in 2012 waren dit er 3,3 miljoen op bijna 17 miljoen inwoners (Oosterveer, 2013). Daarnaast wordt gezegd dat Nederlanders de meest aanwezige en actieve gebruikers van sociale media zijn (Dugan, 2012; Woollaston, 2013). ${ }^{6}$

\subsection{Multi-method onderzoek: gebruiksstatistieken en diepte-interviews}

In het empirische deel van deze studie zullen we dieper ingaan op de vragen uit de theoretische sectie, kijkend naar zowel Twitter als Facebook. Door middel van het combineren van kwantitatieve en kwalitatieve bronnen onderzoeken we zowel het algemene gebruikspatroon van politici als de rol die partijen en hun campagnestrategie spelen in het al dan niet stimuleren van socialemediagebruik door kandidaten. Daarbij staan verschillen tussen partijen centraal, waardoor de kwalitatieve en kwantitatieve uitkomsten met elkaar te vergelijken zijn. Zodoende komen we tot conclusies met zowel enige externe als interne validiteit.

\subsection{Aanwezigheid van politici op sociale media}

De kwantitatieve analyse laat zien hoeveel kandidaten gebruikmaken van sociale media en hoe dit gebruik binnen verschillende partijen is verdeeld over de kandidaten. Van alle 531 kandidaten van de 11 lijsten die in 2012 minimaal 1 zetel wisten te bemachtigen tijdens de Tweede Kamerverkiezingen hebben we geregistreerd of ze een account hadden op verschillende sociale media de dag voor de verkiezingen, en hoeveel volgers zij op dat moment hadden. De data betreffen dus de campagneperiode. Deze gegevens zijn beschikbaar voor Twitter en Facebook. ${ }^{7}$ De plek op de lijst koppelden we hieraan en die beschouwen we als een indicator voor welke kandidaten hoger staan in de interne partijhiërarchie en meer prominent zijn (in het licht van onze eerste en tweede onderzoeksvraag). Voor Twitter was het ook mogelijk om een blik te werpen op het bereik middels het aantal geposte berichten (tweets) in de campagneperiode, gemeten als het dagelijks gemiddelde aantal berichten in de maand voorafgaande aan de verkiezingen (zie Jacobs \& Spierings, 2014). Aangezien we hier de volledige populatie van kandidaten bekijken, baseren we de analyses op beschrijvende statistiek. Deze gegevens zijn deels handmatig en deels geautomatiseerd verzameld (zie Jacobs \& Spierings, 2014). 


\subsection{Interviews}

In het kwalitatieve deel van de analyses staat de rol van de partij centraal: in hoeverre worden lijsttrekker en kandidaten gestimuleerd, gefaciliteerd, weerhouden of verboden om actief te zijn op sociale media en hun eigen kandidatuur in tegenstelling tot de partij in het voetlicht te zetten. Om inzicht in deze processen en afwegingen te krijgen, hebben we diepte-interviews van gemiddeld ongeveer een uur uitgevoerd met veertien politici en socialemediaverantwoordelijken (juli 2013-november 2014). Deze interviews omvatten alle partijen met uitzondering van de radicaal-rechtse PVV en de ouderenpartij 50PLUS. Voor het classificeren van de afzonderlijke partijen als meer of minder gecentraliseerd zijn helaas geen standaardcriteria voorhanden. De literatuur over politieke partijen suggereert dat zogenaamde "mass parties" en "business firm parties" vaker strak en gecentraliseerd zijn, terwijl "catch-all" en "cadre parties" in de regel meer ruimte geven aan hun vertegenwoordigers (Krouwel, 2006). Uiteraard gaat het hier meer om een continuüm en is elke classificatie daarom ietwat arbitrair. De sectie over partijorganisatie in het standaardwerk over Nederlandse politiek door Andeweg en Irwin (2008) geeft bijvoorbeeld geen expliciete classificatie van de partijen. De partijen werden door ons als volgt geclassificeerd: SGP, 50Plus, SP, Partij voor de Dieren en PVV werden beschouwd als sterk gecentraliseerd, terwijl vooral GroenLinks en PvdA als zwak gecentraliseerd werd beschouwd. D66, ChristenUnie, CDA, en VVD bekleedden een middenpositie ('matig gecentraliseerd').

In verband met de gevoeligheid van campagne-informatie is met de respondenten afgesproken om hen in de tekst niet bij naam of partij te noemen. Appendix 1 geeft wel een overzicht van de geïnterviewden en hun functie. Voor meer informatie kan contact opgenomen worden met de auteurs.

\section{Analyses}

We schetsen hier eerst een overzicht van het gebruik van verschillende sociale media, voornamelijk kijkend naar het verschil tussen alle kandidaten, de topkandidaten (top 10) en de lijsttrekker (Sectie 4.1). Daarna kijken we naar de rol van de partijen en hoe de algemene partijcampagne en socialemedia-account zich verhouden tot het gebruik door individuele politici (Sectie 4.2). Ten slotte zullen we deze empirische resultaten koppelen aan partijkenmerken (Sectie 4.3). 


\subsection{Wie gebruikt sociale media?}

De aanwezigheid van Nederlandse politici op sociale media is groot en is in hoog tempo gegroeid. In 2010 had al één op de drie Tweede Kamerkandidaten een Twitteraccount (34 procent) (Spierings \& Jacobs, 2014); in 2012 was dit drie op de vier (76 procent). ${ }^{8}$ Voor Facebook is dit 72 procent, waar de Nederlandse equivalent Hyves in 2010 nog door 46 procent van de politici gebruikt werd (Spierings \& Jacobs, 2014) (dat is in 2012 gezakt naar 27 procent en in 2014 is Hyves opgeheven). In totaal had in 201288 procent van de kandidaten een account op minstens één van deze drie sociale media.

De variatie tussen kandidaten is groot, maar gemiddeld hadden ze ruim 4.000 volgers op Twitter. De kandidaten die in 2010 al actief waren hadden gemiddeld ruim 12.000 volgers in 2012 (Jacobs \& Spierings, 2014; Spierings \& Jacobs, 2014). Deze aantallen zijn wel zeer scheef verdeeld met enkele zeer populaire politici. Zelfs in de top 5 zien we nog een duidelijke kloof tussen de eerste drie en de rest: Arjan El Fassed (GL), 266.000; Geert Wilders (PVV), 209.000; Alexander Pechtold, 163.000 (D66); Diederik Samsom (PvdA), 71.000; en Jolande Sap (GL), 53.000.10 Vier van deze vijf kandidaten waren op dat moment lijsttrekker voor hun partij. Zij zijn gemiddeld genomen ook actiever: de 11 lijsttrekkers plaatsen gemiddeld 22 tweets per persoon per dag in de campagneperiode, terwijl de andere $390 \mathrm{kan}$ didaten met een account gemiddeld 9 keer per dag tweetten. Het verschil tussen top 10-kandidaten ( 2 tot en met 9) en de rest is relatief klein: 11 versus 9 tweets per dag. Deze cijfers zijn afhankelijk van enkele zeer actief tweetende politici. Zo bevinden alleen de lijsttrekkers Pechtold, Samsom en Thieme zich tussen de 10 procent (53) meest tweetende kandidaten. De eerstvolgende (Henk Krol) staat pas op plaats 145 van de 531 . Onder de 10 procent meest-tweetende kandidaten bevinden zich, naast de drie lijsttrekkers, 16 andere top 10-kandidaten en dus niet minder dan 34 kandidaten die lager op de lijst staan. ${ }^{11}$

We zien dus dat zeker niet alleen de topkandidaten zich op sociale media begeven en dat de meest actieve Twitteraars zowel op de top als op lagere plekken te vinden zijn. Dit lijkt te duiden op meer diffuse individualisering, omdat tal van politici via sociale media aandacht vragen van het publiek. Tegelijkertijd zien we dat de toppolitici, in het bijzonder lijsttrekkers, actiever zijn. Ook lijkt het publiek, uitgedrukt in het aantal volgers van politici, zich vooral te richten op de lijsttrekkers. Dat is eerder een indicator van geconcentreerde individualisering, ofwel presidentialisering, zeker als we ons realiseren dat we hier kijken naar accounts die persoonsgebonden zijn en allereerst de politica of politicus presenteren en pas in latere instantie de partij. Hoewel de verschillende resultaten aldus wijzen op geconcentreerde individualisering, is voor het grotere publiek de aanbodzijde (nog los van het aantal tweets) echter niet onbelangrijk, gezien het indirect bereik van sociale media via de traditionele media, in het bijzonder kranten. 
In Figuur 1 bekijken we de aanbodzijde in meer detail voor Twitter en Facebook als dominante sociale media in de Nederlandse politiek. De x-assen in Figuur 2 geven per partij het percentage van kandidaten dat een account heeft op Twitter en Facebook in 2012. ${ }^{12}$ Vergelijkbaar hebben we op de y-as het percentage weergeven voor de top tien per kandidatenlijst. ${ }^{13}$ Hoe dichter een partij bij de diagonaal ligt, des te meer deze percentages overeenkomen. Als de stip boven de diagonaal ligt, is de top tien meer aanwezig dan het gemiddelde van alle kandidaten (gefocuste individualisering); ligt de stip eronder, dan is de aanwezigheid sterker onder alle kandidaten dan onder de top tien (diffuse individualisering). Alle lijsttrekkers hebben een account op zowel Twitter als op Facebook (een indicator voor presidentialisering als specifieke vorm van gefocuste individualisering).

Naast de lijsttrekkers is ongeveer twee derde of meer van alle kandidaten aanwezig op de sociale media; de kandidaten van de SGP, PVV (alleen voor Twitter) en 50Plus vormen een uitzondering. Kijken we specifiek naar de top 10 per partij, dan zien we een diffuser patroon en een wat grotere middengroep aan partijen die licht verschilt per platform. Wederom behoren de SGP en 50Plus tot de partijen met de minste top tien-kandidaten op sociale media. Kortom, de spreiding onder partijen is aanzienlijk, maar tegelijkertijd is bijna in alle gevallen een meerderheid van de kandidaten actief op Twitter en Facebook.

Voor personalisering is ook de verhouding tussen de lijsttrekker, top tien en alle kandidaten van belang. Ten eerste, indachtig dat alle lijsttrekkers op Twitter en Facebook te vinden zijn, toont een positie dichter naar de linkeronderhoek van de figuren een sterkere presidentialisering voor een partij. Dat is het sterkst bij de partijen waarvan het kleinste aantal kandidaten actief is op sociale media, zoals 50Plus, SGP en PVV. Voor Facebook is echter geen enkele partij in het kwadrant linksonder te vinden. Ten tweede kunnen we de top tien met alle kandidaten vergelijken. Dan valt op dat in de meerderheid van de gevallen (16 van de 22) de top 10 net wat meer aanwezig is dan alle kandidaten gemiddeld. Ook valt direct op dat eigenlijk alle partijen vrij dicht bij de diagonaal te vinden zijn. De grootste afstand vinden we voor de Twitteraanwezigheid van de PvdD: alle eerste tien kandidaten hebben een account, maar in totaal is dit 'slechts' 72 procent voor alle kandidaten; net iets meer dan de helft van de kandidaten op plekken 11 tot en met 25 (de lengte van de PvdD-lijst) had een account op Twitter. Dit is meteen het grootste verschil. Al bij al zien we dus dat de focus vooral ligt op de lijsttrekkers en dat de verschillen binnen een partij verder beperkt zijn. Daarbij valt tevens op dat op Twitter het verschil tussen partijen groter is dan op Facebook, en dat in beide gevallen de presidentialisering sterker lijkt bij de minst gecentraliseerde partijen (GL, PvdA), zeker in vergelijking met de meest gecentraliseerde partijen (SGP, PVV, 50Plus, SP, PvdD), die we relatief vaak in de linkeronderhoek vinden.

RES PUBLICA • $2015-1$ 

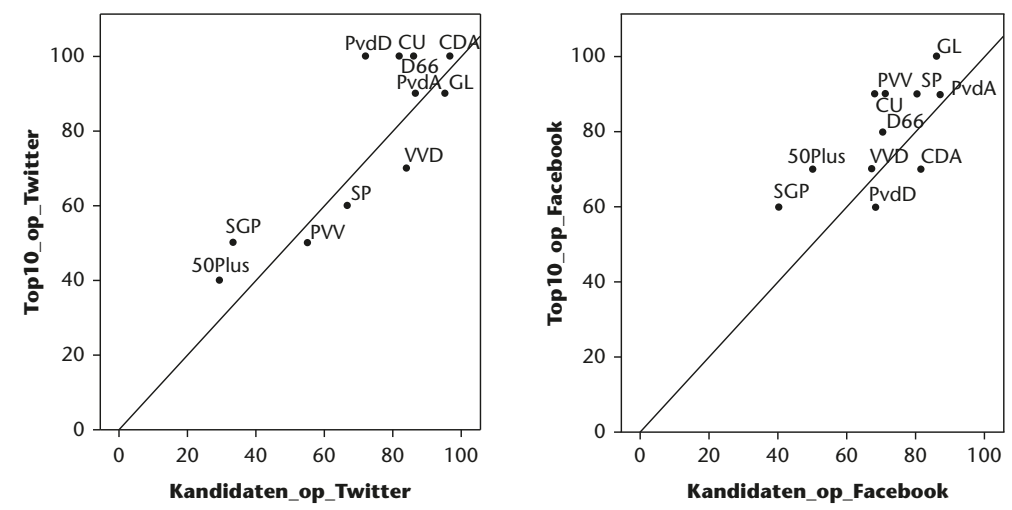

FIGUUR 1. Aanwezigheid van kandidaten, top 10-kandidaten en lijsttrekkers op Twitter en Facebook per partij in 2012.

\subsection{Verschillen in Facebook- en Twittergebruik?}

In de vorige paragraaf gingen we vooral in op het type personalisering dat sociale media in de werkelijkheid lijken te stimuleren ( $c f$. onderzoeksvraag 1). Hier gaan we op basis van interviews dieper in op het verschil tussen Twitter en Facebook (onderzoeksvraag 2) en onderzoeken we in meer detail of het type partij ertoe doet (onderzoeksvraag 3).

Alle geïnterviewde partijen zijn het erover eens dat Twitter een persoonlijk medium is, maar dat Facebook vooral ook gebruikt kan worden door de partij. Zoals een socialemediaverantwoordelijke het verwoordt: Facebook is "toch wel een beetje het zwaartepunt. (...) Een Twitteraccount van een partij is gewoon minder waardevol dan accounts van politici” (Partij 6, 25 april 2014). Dit reflecteert zich in de volgerscijfers. Zo had de PvdA begin oktober 2013 zo'n 30.000 volgers op Twitter, maar partijleider Samsom had er bijna 120.000. Hetzelfde beeld zien we bij de andere grote partij, de VVD, die bijna 50.000 volgers had; partijleider Mark Rutte heeft als minister-president bijna 200.000 volgers. ${ }^{14}$ De partijen focussen zich voor de partijpagina op Facebook. De partijhoofdkwartieren voorzien daarnaast wel in Twitterondersteuning en allemaal hebben ze socialemediaverantwoordelijken. Dit betekent echter niet dat de partijen voor politici gaan Twitteren: "Twitter moet je echt zelf doen. Doe je dat niet [zelf], dan kun je erop wachten totdat je aan de schandpaal genageld wordt" (Partij 1, 25 november 2013).

Het grote verschil tussen Twitter en Facebook lijkt het publiek te zijn: Op Twitter bevinden zich de opinieleiders, journalisten en andere politici; Facebook geeft rechtstreeks toegang tot de kiezer. Twitter heeft als grootste voordeel "het feit dat veel gebruikers van sociale media journalisten zijn van de traditionele media, die 
dat dan weer terugkatapulteren naar de gewone media” (Partij 9, 24 augustus 2013). Alle partijen halen aan dat Twitter sowieso interessant is vanwege de aanwezige journalisten. Maar dat heeft ook zo zijn nadelen: "Landelijke journalisten hebben hun Twitterlijsten klaar, zitten gewoon te wachten (...) dat er ergens eentje uitglijdt, dus dat is voor ons een heel spannend proces. Dat betekent het gesprek aan te gaan [met onze politici] en qua bewustwording weer een stapje verder te helpen" (Partij 5, 4 oktober 2014). Het feit dat journalisten prominent op Twitter aanwezig zijn, betekent met name dat politici rechtstreeks met journalisten in contact kunnen komen: "Ik volg een paar journalisten. (...) Je kan bij allerlei mensen, om zo te zeggen, als het ware inbreken, je kan er gewoon contact mee leggen" (Partij 8, 13 september 2013). Dat betekent niet dat de journalisten ook altijd antwoorden, maar Twitter breekt wel de macht van de partij: “Je moet sowieso een hoop controle uit handen geven. Je bent niet meer de baas, jij bent [als campagneleider] niet meer de enige die lijntjes heeft naar de media (Partij 8, 13 september 2013). Partijen erkennen dus dat Twitter het potentieel heeft om een bredere, diffuse personalisering teweeg te brengen.

Partijen zien Facebook als veel minder gevaarlijk, omdat het complexer en mede daardoor minder aantrekkelijk is voor individuele politici. Zoals een geïnterviewde politica het verwoordt: “Op Facebook wil iedereen ook weer een plaatje en heb je een heleboel persoonlijke meuk van mensen. (...) Bij Twitter hoef ik daar helemaal geen rekening mee te houden” (Partij 9, 3 juli 2013). Het algoritme van Facebook beloont inderdaad makkelijk ‘deelbare' content zoals foto's. Goede foto's met tekst of infographics vergen echter meer expertise en tijd, en hier zijn partijen in het voordeel boven de individuele politici. Daarnaast is het zo dat journalisten Facebook meestal negeren, deels omdat profielen veel minder vaak openbaar zijn. Zonder journalisten valt voor politici de feedbackloop naar de traditionele media, een belangrijk voordeel van Twitter, weg. De meeste politici gebruiken Facebook voornamelijk als persoonlijk en Twitter als publiek medium. Met Twitter kunnen ze hun "geloofwaardigheid" opbouwen (Partij 5, 4 oktober 2013). Het is dan ook gemakkelijker om politici te overtuigen van het nut van Twitter: "Als ik tegen ze zeg: 'kijk je verstuurde toen die en die tweet en nu staat het op nu.nl', dan groeit het ego al enorm” (Partij 4, 14 oktober 2014) en "[Je] kan ze dat ook niet kwalijk nemen, omdat ze altijd gericht waren op de traditionele media” (Partij 3, 25 september 2014). Socialemediaverantwoordelijken hebben veel meer moeite om hun politici te overtuigen van het nut van Facebook: "eigenlijk zegt het ze niet zoveel. Ze onderschatten soms de impact” (Partij 3, 25 september 2014). Of overtuigen lukt geheel niet: bij acht van de negen partijen beheren de socialemediaverantwoordelijken minstens een deel van de Facebookpagina's; voor Twitter is dat slechts bij vier van de negen partijen.

Twitter zou in theorie diffuse individualisering tot gevolg kunnen hebben. Goed Facebookgebruik vergt meer expertise, financiën en ondersteuning. Omdat Face-

RES PUBLICA • $2015-1$ 
book minder door journalisten gebruikt wordt, heeft het ook minder aantrekkingskracht als politiek (in plaats van privé) medium voor politici. Deze informatie relativeert de kwantitatieve resultaten voor Facebook, maar werpt nieuwe vragen op voor Twitter. De gebruikscijfers toonden eerder geconcentreerde personalisering in de vorm van presidentalisering (ten minste voor een aantal partijen) en niet zozeer diffuse individualisering, terwijl dit potentieel wel door campagnemanagers erkend wordt.

\subsection{Sociale media, controle over de boodschap en strakke partijhiërarchie}

Het lijkt dat vooral Twitter de media-aandacht voor een partij of kandidaat kan vergroten, maar tevens de macht van de partijleiding kan verminderen. Heeft dit gevolgen voor het stimuleren van Twittergebruik door partijen? Het lijkt erop dat alle partijen vinden dat sociale media niet genegeerd kunnen worden, maar er zijn twee verschillende benaderingen: de behoudende en de meer stimulerende. Vijf partijen stimuleren Twittergebruik actief, terwijl twee partijen vaak actief op de rem gaan staan. Bij de twee overige partijen is er geen expliciet beleid op dit punt. Aan het ene uiterste vinden we een sterk gecentraliseerde partij die haar politici het volgende meegeeft: "ga alleen Twitteren als je je daar prettig bij voelt. (...) Doe dat niet omdat het zogenaamd moet of zo" (Partij 1, 25 november 2013). De tweede behoudende (en wederom sterk gecentraliseerde partij) zegt iets gelijkaardigs: "Of je doet het goed, of je doet het niet” (Partij 2, 21 november 2014). Deze partijen moedigen minder aan en legitimeren expliciet ruimte om niet actief op Twitter te gaan of benadrukken zelfs de gevaren. Aan de andere kant zijn er partijen die alle politici expliciet aansporen een Twitter-account te openen. Zoals een politica van een partij aangaf in het interview: "ik ben op Twitter gegaan toen ik kandidaat was voor de Tweede Kamer. Ook op nadrukkelijk verzoek van het campagneteam. (...) Er is ook het nadrukkelijk verzoek vanuit de partij om frequenter te Twitteren" (Partij 7, 4 november 2013) en dit werd bevestigd door de socialemediacampaigner (Partij 7, 23 december 2014). ${ }^{15}$ Toch stimuleren ook sommige gecentraliseerde partijen hun politici in meer of mindere mate om een Twitteraccount te openen. De relatie is dus niet eenduidig.

De meeste partijen mogen hun politici relatief vrij laten in de keuze om op Twitter te gaan of niet, ze houden allemaal wel een oogje in het zeil wanneer de politici Twitter daadwerkelijk gebruiken - vooral tijdens de campagne. Een socialemediaverantwoordelijke: “Kijk, we waren met zijn tweeën... als je gewoon een goed programmaatje hebt dat alle tweets [van de kandidaten] onder elkaar zet, dan is het gewoon puur heel simpel afwerken. Dan zie je ook meteen wie er niet heeft gereageerd en zo moet je ook wel selectief zijn. Een vraag beantwoord je, 
een mening kan je dan bekijken zo van kijk eens even hier op de website" (Partij 9, 21 augustus 2013). De socialemediaverantwoordelijke voor een sterk gecentraliseerde partij beschrijft de werkwijze van zijn partij als volgt: "Het gebeurt wel eens dat we elkaar dan bellen of mailen. Van joh is dat nou wel zo verstandig. (...) dat je een beetje meekijkt, ja dat vind ik niet zo gek" (Partij 1, 25 november 2013).

Als elke politicus haar of zijn eigen communicatiekanaal heeft, loopt een partij het gevaar dat een kakofonie aan tweets ontstaat. De meeste partijen stemmen dan ook met hun politici af wie waarover tweet. Bij sommige sterk gecentraliseerde partijen is dat op formele basis: "speciaal voor het online campagneverhaal hebben we een online campagneleider gekregen, (...), die was politiek verantwoordelijk" (Partij 5, 4 oktober 2013). Bij matig gecentraliseerde partijen is dat vaak op informele basis: "dat is eigenlijk heel natuurlijk ontstaan. Er zijn geen richtlijnen over gegeven. Maar als een onderwerp politiek een beetje breed is dan overleggen we meestal toch even met elkaar in welke richting we daarover zullen antwoorden" (Partij 7, 4 november 2013).

TABEL 1. Overzicht van de citaten gerelateerd aan de Twitterstrategieën.

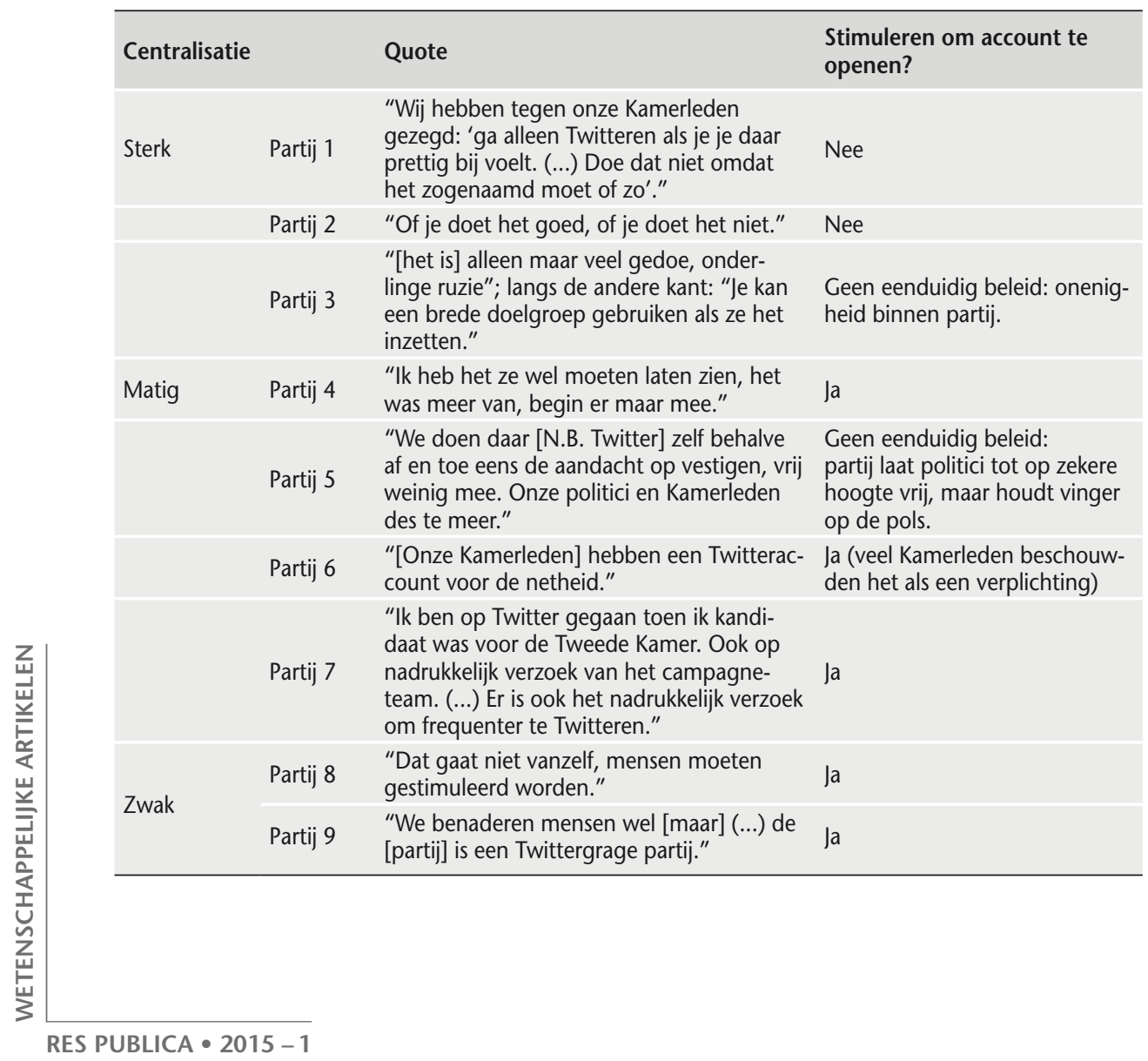


Een belangrijke kanttekening is hier dat het de partij in kwestie electoraal voor de wind ging. Een tweede, gelijkaardige maar zwak gecentraliseerde partij ging het electoraal niet voor de wind en zij had hier veel meer problemen mee, omdat interne partijspanning doorlopend tot uiting kwam op sociale media. Als informeel overleg faalt, kan een dergelijke partij de controle vervolgens niet teruggrijpen: "we hadden een voorlichter die helemaal overspannen was met het gedoe en die ging op een gegeven moment de hele tijd naar mensen bellen van 'he dat mag je niet zeggen'. Ja, dan ben je verkeerd bezig, dat was gewoon de stress” (Partij 8, 13 september 2013).

Het onderscheid tussen sterk, matig en zwak gecentraliseerde partijen heeft dus beperkingen, aangezien zelfs de meest gedecentraliseerde partijen een oogje in het zeil houden. De bevinding van Norris en collega's (1999) lijkt ook voor sociale media op te gaan: partijen willen toch een zekere mate van controle over de centrale boodschap behouden. De vrijheid van de individuele politici is niet onbeperkt. De mate van centralisatie lijkt wel een versterkende rol te spelen in controle en verzwakking in stimulans, wat aansluit op de bevinding van onze kwantitatieve analyse dat sterk gecentraliseerde partijen een gemiddeld genomen sterkere presidentialisering vertonen.

\section{Conclusie}

In dit stuk onderzochten we hoe sociale media als Twitter en Facebook personalisering in de hand werken. Hoewel er relatief veel kwantitatief onderzoek is dat suggereert dat sociale media een nieuwe, persoonlijkere campagnestijl stimuleren ( $c f$. Vergeer et al., 2013), wordt zelden of nooit een onderscheid gemaakt tussen verschillende types personalisering. Ook is nog onduidelijk of dit gelijk geldt voor alle sociale media. Tot slot werd nog nooit onderzocht in hoeverre partijen een rol spelen in het actief worden van hun kandidaten op sociale media. Om een antwoord te krijgen op drie onderzoeksvragen die we op die thema's formuleerden, gebruikten we kwantitatieve en kwalitatieve gegevens over Twitter en Facebook in de Nederlandse politiek.

Sociale media zijn op dit moment wijdverspreid onder de Nederlandse politici: driekwart van de kandidaten van de verkiezingen van 2012 had een Twitteraccount en bijna 90 procent van de kandidaten was actief op minstens één van drie sociale media (Facebook, Twitter, Hyves). De resultaten geven ook aan dat alle partijen het belang van sociale media inzien in deze fase van het diffusieproces. Alle partijen hebben een verantwoordelijke voor sociale media, al is dat vaak een deeltijdbaan. Tegelijkertijd suggereren onze gebruikscijfers dat sociale media meer gebruikt worden door lijsttrekkers (100\%) dan door de gemiddelde kandidaat $(76 \%)$ of de gemiddelde top 10-kandidaat (77\%). Hier zien we dus tekenen van presidentialisering of (zeer) gefocuste individualisering die vooral de machtsverhoudingen binnen par- 
tijen normaliseert. Dit patroon komt terug aan de vraagzijde: lijsttrekkers hebben relatief veel volgers. Tot dusverre het voorlopige antwoord op onderzoeksvraag 1: In welke mate zorgt socialemediagebruik voor gefocuste dan wel diffuse personalisering?

De antwoorden op onderzoeksvraag 2 - Is er een verband tussen de verschillen in soorten sociale media, in casu Twitter en Facebook, en de verschillende soorten personalisering? - en onderzoekvraag 3 - Hoe gaan partijen om met het socialemediagebruik van hun politici en verschilt dit voor gecentraliseerde en nietgecentraliseerde partijen? - lijken sterk samen te hangen. In het meeste onderzoek naar sociale media wordt vooral naar Twitter gekeken. Alle lijsttrekkers zijn actief op sociale media, net als een grote meerderheid van de andere kandidaten. Tegelijkertijd zijn er wel degelijk verschillen tussen partijen wat betreft minder prominente kandidaten en politici, en in mindere mate de top tien-kandidaten. Maar zoals een socialemediaverantwoordelijke opmerkt: "Facebook en Twitter hebben ongeveer net zoveel te maken met elkaar als radio en televisie” (Partij 6, 4 oktober 2013). Vooral Twitter is erg persoonlijk en biedt eerder uitdagingen dan mogelijkheden voor partijen. Op Twitter verdwijnen partijen nog meer op de achtergrond en heerst het gevaar dat een kakofonie aan partijmeningen de digitale wereld ingestuurd wordt. Het vergt voor partijen meer afstemming. Facebook biedt meer mogelijkheden om de partijboodschap te verspreiden en lijkt vooralsnog minder interessant - politiek gezien dan - voor politici dan voor partijen als geheel. Facebook lijkt momenteel weinig impact te hebben op personaliseringprocessen, aangezien politici het nauwelijks politiek gebruiken, het meer expertise vereist (om bv. infographics te maken) en het medium minder gebruikt wordt door journalisten. Hierdoor is het vrijwel ongevaarlijk voor partijen. Twitter is veel gevaarlijker: het is snel, kort, makkelijk te gebruiken en goedkoop. Journalisten houden Twitter nauwlettend in de gaten en het risico op uitglijders is reëel, vooral wanneer een partij er slecht voorstaat en er interne onvrede is. Bovendien hebben de partijhoofdkantoren en voorlichters door Twitter niet meer het monopolie op de lijntjes met journalisten. Twitter bevordert potentieel dus diffuse individualisering, maar zelfs deze potentie moeten we niet overdrijven: aandacht en naambekendheid voor lager geplaatste politici hangt erg af van spillover naar traditionele media via de op Twitter aanwezige journalisten. Vooral bij uitglijders is de kans op aandacht groot, ook voor minder bekende politici, maar het is de vraag of dat in het voordeel is van de politici in kwestie.

In elk geval lijken partijen een dubbele houding te hebben: enerzijds stimuleren ze kandidaten vaak om individueel actief te worden op Twitter, maar anderzijds houden ze in de meeste gevallen een vinger aan de pols. Is deze houding afhankelijk van de partijstructuur? Gecentraliseerde partijen zijn door de bank genomen wat terughoudender, hoewel alle soorten partijen over het algemeen toch een zekere mate van toezicht op de boodschappen van hun kandidaten houden, wat

RES PUBLICA • $2015-1$ 
de mogelijkheden voor meer diffuse individualisering verder beperkt. Ook in de kwantitatieve analyse zagen we dat het gat tussen lijsttrekker en andere kandidaten gemiddeld wat groter was bij de sterker gecentraliseerde partijen.

Hoewel de patronen in deze verkennende studie aardig robuust zijn, is deze studie slechts een eerste stap in het vinden van antwoorden op de vragen waarmee we begonnen zijn en in het begrijpen van de relaties tussen partijstructuur, socialemediaplatforms en typen personalisering. Onze analyse suggereerde verschillende nieuwe vragen, waarvan we er twee willen benadrukken. Allereerst hebben wij voornamelijk gekeken naar de aanbodzijde van socialemediagebruik, terwijl zowel politici als campaigners het doorsijpelen van berichten naar de traditionele media, zoals kranten en televisie, als een kernfacet van Twitter zien. Of en welke berichten van Nederlandse politici een bereik krijgen buiten het 'salon' dat Twitter is, is vooralsnog onbekend en vraagt om meer onderzoek. Ten tweede lag in deze studie de nadruk op individualisering en niet op de privatiseringsdimensie van personaliseringprocessen. Sociale media kunnen ook een effect hebben op de inhoud van berichtgeving over politici. Onze interviewdata over Facebook suggereren dat politici juist hun privéleven lijken af te schermen, maar het type bericht (privé of politiek) op verschillende sociale media verdient meer aandacht alvorens een brede conclusie wordt getrokken over de impact van sociale media op de personalisering van de politiek.

In alle gevallen geldt dat Twitter meer risico's inhoudt voor partijen waar individuele ontevreden politici profileringsdrang hebben. Als het goed gaat, gaat het ook goed op sociale media. Toch is Twitter in zekere zin een traag medium: "het is op Twitter redelijk lastig om je 'followers' base' op te bouwen. Dat is een redelijk traag proces, tenzij je een bekend politicus bent” (Partij 5, 4 oktober 2013), wat betekent dat een opkomend politicus lange tijd moet bouwen aan een fanbase vooraleer het stadium van de onafhankelijkheid bereikt is. Waar individuele kandidaten echter al macht hebben, worden ze nog machtiger. Dat kan mogelijk verklaren waarom het theoretisch potentieel van Twitter tot diffuse personalisering zich niet lijkt om te zetten in daadwerkelijke personalisering, maar wel voornamelijk de positie van lijsttrekkers, die varen op partijbekendheid en -ondersteuning, lijkt te versterken.

\section{Noten}

1. Of zoals Herbst (2011, p. 95) het mooi verwoordt: "the conversation of the salons reflected and shaped the culture of France and much of Western Europe and ignited the revolutions that would change our world forever. We do not take the salons lightly now; they are invaluable to historians. And we should treat the internet in precisely the same way". 
2. Voor een analyse van de privatisering van de politiek in sociale media, zie bijvoorbeeld Kruikemeier (2014).

3. Zie bijvoorbeeld: http://www.socialbakers.com/blog/147-how-often-should-youpost-on-your-facebook-pages.

4. Het ANP is het belangrijkste Nederlandse persbureau.

5. Partijen zijn zich vaak bewust van deze gevaren en gebruiken de termen Twitterstorm, Facebookflater of 'een Boekestijntje' naar het VVD-Kamerlid dat in grote problemen kwam door een Twitter-uitschuiver.

6. De internetpeneratiegraad is ruim boven de $90 \%$.

7. Waar relevant zullen we ook melding maken van vergelijkbare gegevens voor Hyves.

8. Van alle kandidaten heeft $70 \%$ daadwerkelijk getweet in de maand voor de verkiezingen. De andere 27 kandidaten met een Twitteraccount hebben niet getweet in deze periode, maar dit zijn niet allemaal zogenoemde 'Twitterzombies'. Sommigen hebben simpelweg niet in die periode getweet, maar waren voor en na die periode wel degelijk actief op Twitter. Voor 2010 is een vergelijkbare statistiek voorhanden voor de laatste week voor de verkiezingen en dan is het aantal actief Twitterende kandidaten $28 \%$, wat een vergelijkbaar gat van ongeveer 6 procentpunten laat zien als in 2012. Voor Facebook en Hyves zijn dergelijke gegevens niet beschikbaar.

9. Arjan El Fassed heeft een grote schare (buitenlandse) volgers overgehouden aan zijn webactiviteiten in en rond de mensenrechtenkwestie in de Palestijnse gebieden.

10. Het gaat hier om afgeronde cijfers.

11. De gemiddelde plek op de lijst van deze 34 kandidaten is 27, variërend van 12 tot en met 56 .

12. Voor Twitter kunnen we een vergelijkbare analyse uitvoeren voor het percentage kandidaten dat in de campagneperiode ook minimaal 1 tweet heeft geplaatst; we kunnen 'Twitterzombies' verwijderen. De verdeling van de 27 kandidaten die wel een account hadden maar geen tweet plaatsten in die maand is als volgt (tussen haakjes het aantal top 10-kandidaten): CDA 3(0); D66 5(2); GL 3(0); PvdD 2(0); PVV 7(1); SGP 2(0); SP 1(0); VVD 3 (3); 50Plus 1(1). Deze kandidaten niet opnemen in Figuur 2 verandert nauwelijks iets aan de duiding in de tekst. De sterkste afwijking

RES PUBLICA • $2015-1$ 
vinden we voor de PVV en in dit geval versterkt het onze conclusies over presidentialisering, omdat de afwezigheid van nog meer kandidaten een relatief sterkere positie voor de lijsttrekker betekent. De positie van partijen ten opzichte van de diagonaal verandert voor twee partijen - GroenLinks, PVV - en wel zodanig dat het de conclusies versterkt: top 10-kandidaten zijn meer op sociale media dan lager geplaatste kandidaten.

13. Uiteraard heeft een top 10-plaatsing een andere betekenis in een grote dan in kleine partij (in termen van zetels). Een top 3 of top 5 gebruiken maakt de meting echter zeer gevoelig voor individueel gedrag; een verschillend aantal per partij gebruiken maakt deze meting heel arbitrair. Deze argumenten negerend, zien we wel dat van alle top 3-kandidaten (33) er slechts 4 geen Facebookaccount hebben (VVD, PVV, 50Plus, PvdD) en eveneens 4 geen Twitteraccount (PVV x 2; 50Plus x2). Kortom, met een nauwere bandbreedte vinden we vergelijkbare patronen.

14. Natuurlijk valt het onderscheid niet zo scherp te maken: de meeste politici laten op hun Twitteraccount bijvoorbeeld duidelijk zien bij welke partij ze horen en gebruiken de huisstijl van de partij. Ook voor de volgers zou dit een rol kunnen spelen. Zij volgen wellicht ook politici, omdat ze bij een bepaalde partij horen. Politici zijn steeds politicus van een partij en een partij is steeds een geheel van politici.

15. De ironie is overigens dat de politica ook het volgende vermeldde: "Voor zover dat aan ons opdrachten gegeven kunnen worden, want de fractieleden zijn nogal eigenwijs" (Partij 7, 4 november 2013).

\section{Bibliografie}

Andeweg, R. \& Irwin, G. (2005). Governance and Politics in the Netherlands (tweede editie). Basingstoke: Palgrave.

Andeweg, R. \& Irwin, G. (2008). Governance and Politics in the Netherlands (derde editie). Basingstoke: Palgrave.

Colomer, J. (2011). Personal Representation: The Neglected Dimension of Electoral Systems. Colchester: ECPR Press.

Dugan, L. (2012). The US Has The Most Twitter Users, But The Netherlands Is More Active [STATS]. All Twitter, 1 februari 2012. http://www.mediabistro.com/alltwitter/ the-us-has-the-most-twitter-users-but-thenetherlands-is-more-active-stats_b18172.

Gibson, R. \& McAllister, I. (2014). Normalising or Equalising Party Competition? Assessing the Impact of the Web on Election Campaigning. Political Studies. doi: 10.1111/1467-9248.12107. 
Gibson, R. Römmele, A. \& Williamson, A. (2014). Chasing the Digital Wave: International Perspectives on the Growth of Online Campaigning. Journal of Information Technology \& Politics, 11(2), 123-129.

Hansen, K. \& Kosiara-Pedersen, K. (2014). Cyber-campaigning in Denmark: Application and Effects of Candidate Campaigning. Journal of Information Technology \& Politics, 11(2), 206-219.

Herbst, S. (2011). Un(Numbered) Voices? Reconsidering the Meaning of Public Opinion in a Digital Age. In K. Goidel (Ed.), Political Polling in the Digital Age (pp. 85-98). Baton Rouge, LA: Louisiana State University Press.

Jacobs, K. \& Spierings, N. (2014). ... Maar win je er ook stemmen mee? De impact van Twittergebruik door politici bij de Nederlandse Tweede Kamerverkiezingen van 12 september 2012. Tijdschrift voor Communicatiewetenschap, 42(1), 22-38.

Karvonen, L. (2010). The Personalisation of Politics: A Study of Parliamentary Democracies. Colchester: ECPR Press.

Koc-Michalska, K., Lilleker, D., Surowiec, P. \& Baranowski, P. (2014). Poland's 2011 Online Election Campaign: New Tools, New Professionalism, New Ways to Win Votes. Journal of Information Technology \& Politics, 11(2), 186-205.

Kriesi, H. (2012). Personalization of National Election Campaigns. Party Politics, 18(6), 825-844.

Krouwel, A.P.M. (2006). Party Models. In R.S. Katz \& W. Crotty (Eds.), Handbook of Party Politics (pp. 249-269). London: Sage.

Kruikemeier, S. (2014). How Political Candidates Use Twitter and the Impact on Votes. Computers in Human Behavior, 34(1), 131-139.

Lasorsa, D., Lewis, S. \& Holton, A. (2012). Normalizing Twitter: Journalism Practice in an Emerging Communication Space. Journalism Studies, 13(1), 19-36.

McAllister, I. (2007). The Personalization of Politics. In J. Dalton \& H.-D. Klingemann (Eds.), The Oxford Handbook of Political Behavior. Oxford: Oxford University Press.

Norris, P., Curtice, J., Sanders, D., Scammell, M. \& Semetko, H.A. (1999). On Message: Communicating the Campaign. Thousand Oaks: Sage.

Oosterveer, D. (2013). Social media in Nederland 2013: Groei van gebruik Twitter en Facebook afgevlakt. http://www.marketingfacts.nl/berichten/social-media-in-nederland-twitter-en-facebook-het-meest-actief-gebruikt. Geraadpleegd op 13 augustus 2013.

Peterson, R. (2012). To Tweet or not to Tweet: Exploring the Determinants of Early Adoption of Twitter by House Members in the 111th Congress. The Social Science Journal, 49(4), 430-438.

Poguntke, T. \& Webb, P. (Eds.) (2005). The Presidentialization of Politics: A Comparative Study of Modern Democracies. Oxford: Oxford University Press.

Schlozman, K.L., Verba, S. \& Brady, H. (2012). The Unheavenly Chorus: Unequal Political Voice and the Broken Promise of American Democracy. Princeton: Princeton UP. 
Spierings, N. \& Jacobs, K. (2014). Getting Personal? The Impact of Social Media on Preferential Voting. Political Behavior, 36(1), 215-234.

Sudulich, L., Baccini, L. \& Wall, M. (2012). Wired Voters: Internet Exposure and Campaign Effects. Paper Presented at the ECPR Joint Sessions. Antwerpen.

Van Aelst, P., Shaefer, T. \& Stanyer, J. (2011). The Personalization of Mediated Political Communication: A Review of Concepts, Operationalizations and Key Findings. Journalism, 13(2), 203-220.

Van Holsteyn, J. \& Andeweg, R.B. (2012). Tweede Orde Personalisering: Voorkeurstemmen in Nederland. Res Publica, 54(2), 163-191.

Vergeer, M. \& Hermans, L. (2013). Campaigning on Twitter: Microblogging and Online Social Networking as Campaign Tools in the 2010 General Elections in the Netherlands. Journal of Computer-Mediated Communication, 18(4), 399-419.

Vergeer, M., Hermans, L. \& Sams, S. (2013). Online Social Networks and Micro-blogging in Political Campaigning. The Exploration of a New Campaign Tool and a New Campaign Style. Party Politics, 19(5), 477-501.

Vliegenthart, R. (2012). The Professionalization of Political Communication? A Longitudinal Analysis of Dutch Election Campaign Posters. American Behavioral Scientist, 56(2), 135-150.

Woollaston, V. (2013). The Meteoric Rise of Social Networking in the UK: Britons Are the Second Most Prolific Facebook and Twitter Users in EUROPE with a Fifth of over 65s Now Using These Sites. Daily Mail, 13 juni 2013. http://www.dailymail. co.uk/sciencetech/article-2340893/Britons-second-prolific-Facebook-Twitter-usersEUROPE-fifth-aged-65.html.

\section{APPENDIX 1. Overzicht geïnterviewden.}

\begin{tabular}{lll}
\hline & Partij & functie \\
\hline Arjan Vliegenthart & SP & Campagneleider en politicus \\
\hline Maarten Hijink & SP & Socialemediaverantwoordelijke \\
\hline Eva van Esch & Partij v/d Dieren & Socialemediaverantwoordelijke \\
\hline Huub Bellemakers & GroenLinks & Socialemediaverantwoordelijke \\
\hline Lodewijk Bleijerveld & PvdA & Socialemediaverantwoordelijke \\
\hline Mei Li Vos & PvdA & Actieve, high profile politica \\
\hline Jaap Stronks & PvdA & Socialemediaconsultant; adviseur \\
\hline Pia Dijkstra & D66 & PvdA \\
\hline Dieder de Vries & D66 & Actieve, high profile politica \\
\hline Floris Spronk & CU & Socialemediawebcareteam \\
\hline Celina Kremer & CDA & Socialemediaverantwoordelijke \\
\hline Tim Versnel & WV & Socialemediaverantwoordelijke \\
\hline Arnaud Proos & SGP & Socialemediaverantwoordelijke \\
\hline
\end{tabular}


